\title{
Uloge, vrste i važnost dokaza
}

\author{
Ivana Grgić
}

\section{Sažetak}

Dokazi u matematici su izuzetno važni. Dugo se vremena smatralo da je jedina uloga dokaza potvrda ispravnosti matematičkih tvrdnji. U ovom radu ćemo prezentirati druge uloge matematičkih dokaza. Opisat ćemo vrste dokaza, dati nekoliko primjera za svaku vrstu koristeći različite tehnike te pokušati pojasniti važnost dokaza iz pedagoške perspektive.

Ključni pojmovi: matematički dokaz, direktni dokaz, indirektni dokaz, uloge dokaza

\section{Uvod}

Proces utvrđivanja istinitosti neke tvrdnje slijedom logičkih zaključivanja i povezivanja definicija, aksioma i tvrdnji čija je istinitost već poznata, uz zadanu pretpostavku, nazivamo dokazom.

Povijesno gledano, dokaz nije uvijek bio prirodni dio matematičke aktivnosti. U drevnim kulturama u Babilonu, Egiptu i Kini, matematičari su uglavnom bili zainteresirani samo za dobivanje rezultata koji su mogli imati različitu primjenu, a nisu se bavili pitanjem kako su došli do tih rezultata ni mogu li ih poopćiti. Vjerojatno su radili nekakve provjere rezultata, ali ih nisu zapisivali. Tek u grčko doba stvara se deduktivni pristup u matematici i naglasak se stavlja na pitanje osnovanosti, logike i dokazivanja, a ne toliko na samo rješavanje problema i praktičnost [5]. Rad grčkih matematičara u geometriji još od Euklidovih Elemenata (330 - 275 pr. Kr.) bio je model za znanstveno razmišljanje. Tek od 1900tih dokazi u algebri i analizi izvode se s istom logičkom snagom kako je 
napravljeno u Elementima.

Danas je dokazivanje gotovo sinonim za istraživanje u matematici i velika količina dokaza se producira svake godine. Jedan od razloga tomu je što dokazi sadrže informaciju kako možemo dobiti druge važne rezultate i često sadrže tehnike primjenjive za rješavanje drugih problema. $\mathrm{Na}$ primjer, Arhimedov rezultat o volumenu sfere je, naravno, zanimljiv zbog primjene računanja volumena sfere, ali bez dokaza bi bilo teško naći volumene drugih tijela. Arhimed je opisao metodu koju je koristio da dođe do formule. Ta metoda je oblik integriranja i zanimljiva je za brojne druge primjene.

Postoji konsenzus među matematičarima da dokazi, osim što služe za provjeru rezultata, sadrže još mnogo više zanimljivih informacija. Stoga u sljedećem dijelu razmatramo različite uloge dokaza.

\section{Uloge dokaza}

Ovdje ćemo navesti i objasniti uloge dokaza kao u [9]. To su:

- uvjeravanje,

- objašnjenje,

- sistematizacija,

- otkriće,

- komunikacija.

Jako dugo se smatralo da je uvjeravanje, potvrdivanje ispravnosti matematičkih izjava osnovna uloga dokaza. Prvenstveno želimo uvjeriti sebe, a onda i zainteresiranu publiku. Suprotno vjerovanju mnogih učitelja matematike da jedino dokaz pruža apsolutnu sigurnost $u$ istinitost tvrdnje, matematičari su uvjereni $u$ istinitost svojih rezultata mnogo prije samog konstruiranja dokaza. Dakle, dokaz nije nužno preduvjet za uvjerenost $\mathrm{u}$ istinitost neke tvrdnje. Michael de Villiers (1990.) to lijepo kaže „Uvjerenje nije bijektivna funkcija dokaza”. Uvjerenje osigurava motivaciju za dokaz i obično ovisi o kombinaciji intuicije, kvaziempirijske verifikacije (npr. eksperimentalno i induktivno zaključivanje, točne konstrukcije i mjerenja, numeričke supstitucije i slično) i postojanja logičkog, ne nužno rigoroznog, dokaza.

Iako je često moguće postići zadovoljavajuću razinu sigurnosti u ispravnost neke tvrdnje sredstvima kvazi-empirijske provjere, ta sigurnost općenito ne mora pružiti zadovoljavajuće objašnjenje zašto je neka tvrdnja istinita. Samo potvrđivanje istinitosti, čak i razmatranje sve većeg broja primjera može podići razinu uvjerenosti $u$ istinitost tvrdnje, ali ako nema osjećaja zadovoljstva i razumijevanja, i dalje postoji jaka potreba za objašnjenjem. Za mnoge matematičare aspekt objašnjenja u dokazu je čak i od veće važnosti od samog aspekta verifikacije. Nisu svi dokazi 
jednako dobri u objašnjavanju. Objašnjenje je kriterij „dobrog” dokaza [3].

Još jedna uloga dokaza je sistematizacija znanja. Dokaz je nezamjenjiv alat $\mathrm{u}$ sistematizaciji raznih poznatih rezultata $\mathrm{u}$ deduktivan sustav aksioma, definicija i teorema. Neke najvažnije uloge deduktivne sistematizacije su:

- pomaže u identifikaciji nekonzistentnosti, kružnih argumenata i skrivenih pretpostavki,

- ujedinjuje i pojednostavljuje matematičku teoriju, povezujući teoreme i koncepte,

- pruža globalnu perspektivu na teoriju otkrivajući aksiomatsku strukturu teme iz koje slijede sva ostala svojstva,

- često vodi do alternativnih deduktivnih sustava,

- korisna je u primjeni unutar i izvan matematike budući da pomaže u provjeri primjenjivosti cijele kompleksne strukture.

Odličan primjer sistematizacije nalazimo u Euklidovim Elementima gdje su skupljeni i sistematizirani mnogi teoremi koje su dokazali grčki matematičari i organizirali ih na takav način da teoremi slijede iz definicija, aksioma i postulata.

Dakle, dokaz nije samo sredstvo a posteriori verifikacije, nego često i sredstvo istraživanja, analize i izuma. U kontekstu formalnog deduktivnog procesa kao što je a priori aksiomatizacija i definiranje, dokaz često može voditi novim otkrićima. Jedan takav primjer je otkriće neeuklidske geometrije. Promjenom petog Euklidovog postulata matematičari su izveli teoreme nekih sasvim novih geometrija.

Dokaz je jedinstven način komuniciranja matematičkih rezultata između profesionalnih matematičara, između predavača i studenata te između studenata i učenika među sobom. Dokaz ima ulogu diseminacije matematičkog znanja u društvu.

Da bismo mogli koristiti dokaz prvo moramo znati pravila zaključivanja, a zatim i tehnike koje možemo koristiti pri dokazivanju. U sljedećem poglavlju je kratki uvod u algebru sudova, tautologije i pravila zaključivanja. Detaljnije se može naći u [10].

\section{Pravila zaključivanja}

\subsection{Algebra sudova}

Sud je bilo koja suvisla izjavna rečenica koja je ili istinita ili lažna. Svakom sudu $A$ pridružujemo vrijednost $\top$ ako je istinit, a vrijednost $\perp$ ako je lažan. Vrijednost istinitosti suda $A$ označavamo sa $\tau(A)$ i nazivamo semantičkom ili istinosnom vrijednošću. Dakle, $\tau(A)=\top$ 
znači da je semantička vrijednost suda $A$ jednaka $\top$, tj. sud $A$ je istinit.

Pomoću logičkih operacija iz jednostavnijih sudova možemo tvoriti nove, složenije sudove. Najvažnije logičke operacije su:

- negacija; sud $\neg A$ je istinit ako je $A$ lažan, a lažan ako je $A$ istinit,

- konjunkcija; sud $A \wedge B$ je istinit jedino ako je istinit i sud $A$ i sud $B$,

- disjunkcija; sud $A \vee B$ je lažan jedino ako su oba suda $A$ i $B$ lažna,

- ekskluzivna disjunkcija; sud $A \vee \underline{ } B$ je istinit jedino ako je jedan od sudova $A$ i $B$ istinit, a drugi lažan,

- implikacija; sud $A \Rightarrow B$ je lažan jedino ako je sud $A$ istinit, a $B$ lažan,

- ekvivalencija; sud $A \Leftrightarrow B$ je istinit jedino ako su vrijednosti istinitosti od $A$ i $B$ jednake.

\subsection{Tautologije, pravila zaključivanja}

Sud $P$ je tautologija ako je $P$ istinit sud bez obzira na istinitost jednostavnih sudova od kojih je sačinjen. U tom slučaju pišemo $\vDash P$, i čitamo „P je tautologija". Navodimo neke važnije tautologije:

(1) $\vDash A \vee \neg A$ (pravilo isključenja trećeg, tj. svaki je sud ili istinit ili lažan, trećega nema),

$(2) \vDash(A \Rightarrow B) \wedge(B \Rightarrow C) \Rightarrow(A \Rightarrow C)$ (pravilo silogizma ili tranzitivnost implikacije),

(3) $\vDash \neg(A \wedge \neg A)$ (zakon neproturječnosti),

(4) $\vDash A \wedge(A \Rightarrow B) \Rightarrow B$ (modus ponens ili pravilo otkidanja).

Pravilo obrata po kontrapoziciji zapisujemo $\vDash(A \Rightarrow B) \Leftrightarrow(\neg B \Rightarrow$ $\neg A)$. Važno pravilo zaključivanja je i pravilo kontradikcije $\vDash(\neg A \Rightarrow$ $\perp) \Rightarrow A$. Riječima, ako je točno da negacija suda $A$ implicira laž, onda je sud $A$ istinit. Sljedeće poglavlje govori o vrstama dokaza i tehnikama dokazivanja.

\section{Vrste dokaza}

Teorem ili tvrdnja je istinit sud čiju istinitost utvrđujemo dokazom. Razlikujemo dvije vrste dokaza: direktni i indirektni. Također, tvrdnje možemo dokazivati matematičkom indukcijom i korištenjem Dirichletovog principa. Za svaku vrstu dokaza donosimo jedan ili dva primjera.

\subsection{Direktni dokaz}

Opis metode: svaki teorem je oblika $A \Rightarrow B$. Direktno dokazati tvrdnju $B$ nekog teorema znači krenuti od pretpostavke $A$, primjenom aksioma, 
definicija i ranije dokazanih teorema, te nizom pravilnih zaključivanja doći do zaključka $B$ [2]

Izrazom $A \Rightarrow B$ indiciramo da kad god je istinit $A$, da i $B$ mora biti istinit (ne možemo imati $A$ bez $B$ ). S druge strane, kad imamo da je $B$ istinit onda ne mora biti da je i $A$ istinit. Ovo se može ilustrirati jednostavnim primjerom „pada kiša $\Rightarrow$ oblačno je”. Ako prihvatimo da kiši, onda automatski prihvaćamo da je oblačno. Međutim, obratno ne mora biti. Prilikom dokazivanja studenti često polaze upravo od tvrdnje koju žele dokazati uzimajući je kao istinitu te zaboravljaju da „izjava $X \Rightarrow$ istinita izjava" ne znači nužno da je izjava $X$ istinita.

Navodimo primjer direktnog dokaza.

Teorem 1. Neka je $n \in \mathbb{N}, n>1$. Ako $n$ nije prost broj, onda $2^{n}-1$ nije prost.

Dokaz. Primijetimo da nam ova tvrdnja daje početnu točku za dokazivanje. Znamo što znači biti prost, pa je razumno početi zapisivanjem broja $n \mathrm{u}$ obliku produkta dva prirodna broja. Dakle, postoje $a, b \in \mathbb{N}$ takvi da je $n=a b, 1<a, b<n$. Promotrimo izraz $2^{a b}-1$ i prisjetimo se identiteta $t^{m}-1=(t-1)\left(1+t+t^{2}+\cdots+t^{m-1}\right)$. Stavimo $t=2^{b}, m=a$. Neka je sada

$$
x=2^{b}-1
$$

i

$$
y=1+2^{b}+2^{2 b}+\cdots+\left(2^{b}\right)^{a-1} .
$$

Tada je

$$
x y=\left(2^{b}-1\right)\left(1+2^{b}+2^{2 b}+\cdots+2^{(a-1) b}\right)=2^{a b}-1=2^{n}-1 .
$$

Budući da je $1<b<n$ imamo da je $1<2^{b}-1<2^{n}-1$ pa je $1<x<2^{n}-1$. Stoga je $x$ pozitivan faktor pa $2^{n}-1$ nije prost broj.

\subsubsection{Dokaz iscrpljivanjem}

U dokazu iscrpljivanjem kao vrsti direktnog dokaza tvrdnja se dokazuje dijeljenjem na konačan broj slučajeva i dokazivanjem svakog od njih zasebno. Zbog široke upotrebe računala ova se metoda sve više koristi iako joj nedostaje matematičke elegancije. Prvi dokaz teorema koji je čak 150 godina intrigirao matematičare, Teorema o četiri boje, dobiven je korištenjem računala i iscrpljivanjem 1936 slučajeva (reducibilnih konfiguracija). Nema gornje granice što se tiče broja slučajeva. Pokazat ćemo jednostavan primjer dokaza iscrpljivanjem.

Teorem 2. Kvadrat bilo kojeg cijelog broja je oblika $3 k$ ili $3 k+1, k \in \mathbb{Z}$. 
Dokaz. Znamo da se svaki cijeli broj može zapisati u obliku $3 q, 3 q+1$ ili $3 q+2$. Dakle, neka je $a=3 q+r$, gdje je $q \in \mathbb{Z}, r=0,1,2$. Onda je

$$
a^{2}=(3 q+r)^{2}=9 q^{2}+6 q r+r^{2}=3\left(3 q^{2}+2 q r\right)+r^{2} .
$$

Kako su $q$ i $r$ cijeli brojevi, onda je i $3 q^{2}+2 q r$ cijeli broj. Stavimo $3 q^{2}+2 q r:=k, k \in \mathbb{Z}$. Imamo $a^{2}=3 k+r^{2}$. Sada razlikujemo:

slučaj I: ako je $r=0$ ili $r=1$ gotovi smo;

slučaj II: ako je $r=2$ onda je $r^{2}=4$ i vrijedi $a^{2}=3 k+4=3(k+1)+1$ što je u traženom obliku.

\subsection{Indirektni dokaz}

Za razliku od direktnog dokaza teorema $A \Rightarrow B$, indirektnim dokazom je put od pretpostavke $A$ do tvrdnje $B$,zaobilazan”. Za svaku tvrdnju $B$ postoji suprotna tvrdnja $\neg B$. Od te dvije tvrdnje, samo je jedna istinita. Indirektni dokaz teorema $A \Rightarrow B$ temelji se na promatranju suprotne tvrdnje $\neg B$ i nastojanju da se dokaže da suprotna tvrdnja nije istinita 6]. Razlikujemo dokaz svođenjem na kontradikciju i dokaz obratom po kontrapoziciji.

\subsubsection{Dokaz kontradikcijom}

Opis metode: kada pokušavamo dokazati $A \Rightarrow B$, pretpostavimo da je $A$ istina, a $B$ nije istina (to jest, negacija od $B$ je istina). Konačnim nizom logičkih zaključivanja dođemo do toga da istovremeno vrijedi neka tvrdnja $T$ i njena negacija $\neg T$, tj. dođemo do tvrdnje koja je u suprotnosti s nekim aksiomom ili ranije dokazanom tvrdnjom. Zaključujemo da negacija tvrdnje $B$ nije istinita, što znači da je $B$ istina. Ova metoda se još naziva reductio ad absurdum. Primjeri dokaza kontradikcijom su sljedeći.

Teorem 3. Skup svih prostih brojeva je beskonačan.

Dokaz. Pretpostavimo suprotno, tj. da je skup $P$ svih prostih brojeva konačan: $P=\left\{p_{1}, \ldots, p_{k}\right\}$, gdje je $p_{k}$ najveći prosti broj. Pogledajmo broj

$$
a=p_{1} p_{2} \cdots p_{k}+1 .
$$

Ovaj broj je sigurno veći od $p_{k}$ te on nije prost jer je $p_{k}$ najveći prosti broj. Ako a nije prost, onda je a složen. Po Osnovnom teoremu aritmetike $a$ se može prikazati kao umnožak prostih brojeva, pa stoga mora biti djeljiv s barem jednim prostim brojem, dakle nekim od brojeva $p_{i}$. 
To je u suprotnosti s pretpostavljenim oblikom broja $a$. Time smo dobili da istovremeno a nije ni složen ni prost, što je nemoguće. Znači da polazna pretpostavka da „prostih brojeva ima konačno mnogo" nije istinita. Istinita je negacija te tvrdnje, tj. polazna tvrdnja teorema.

Teorem 4. Neka je a racionalan broj, b iracionalan. Tada je

(i) $a+b$ iracionalan,

(ii) ako je $a \neq 0$, onda je $a \cdot b$ također iracionalan.

Dokaz. (i) Podsjetimo se što to znači biti racionalan (može se izraziti pomoću razlomka) i iracionalan (ne može se izraziti pomoću razlomka). Dakle, ako želimo pokazati da je $a+b$ iracionalan, to općenito ne znamo zapisati. Umjesto toga, možemo pretpostaviti suprotno, tj. izraziti ga kao racionalan broj što je općenito lako učiniti i pokazati da ovaj pristup vodi kontradikciji. Pretpostavimo suprotno, da je $a+b$ racionalan, tj. $a+b:=\frac{m}{n}, m \in \mathbb{Z}, n \in \mathbb{N}$. Budući da je $a$ racionalan, možemo ga napisati kao $a:=\frac{p}{q}, p \in \mathbb{Z}, q \in \mathbb{N}$. Tada je

$$
b=(a+b)-a=\frac{m}{n}-\frac{p}{q}=\frac{m q-p n}{n q}
$$

što znači da je $b$ racionalan, a to je u kontradikciji s pretpostavkom da je $b$ iracionalan.

(ii) slično.

\subsubsection{Kontrapozicija}

Dokaz obratom po kontrapoziciji zasniva se na ekvivalenciji sudova $A \Rightarrow$ $B$ i $\neg B \Rightarrow \neg A$. Dakle, kada dokazujemo $A \Rightarrow B$ pretpostavimo $\neg B$ i primjenom pravilnog zaključivanja dolazimo do $\neg A$. Pogledajmo jedan primjer.

Teorem 5. Neka je $n \in \mathrm{N}$. Ako $6 \mid n^{2}$, onda $6 \mid n$.

Dokaz. Pođimo od pravila obrata po kontrapoziciji $A \Rightarrow B \equiv \neg B \Rightarrow$ $\neg A$. Neka vrijedi $6 \nmid n$, dokažimo $6 \nmid n^{2}$. Budući da $n$ nije djeljiv sa 6 , to znači da pri dijeljenju sa 6 ima ostatak 1, 2, 3, 4 ili 5. Promotrimo sve prirodne brojeve rasporedene u pet klasa, za $k \in \mathbb{N}_{0}$ :

$$
\begin{aligned}
n= & 6 k+1 \Rightarrow n^{2}=(6 k+1)^{2}=36 k^{2}+12 k+1=6\left(6 k^{2}+2 k\right)+1 ; \text { očito } \\
& \left.n^{2} \text { nije djeljiv sa } 6 \text { (ostatak pri dijeljenju je } 1\right) \\
n= & 6 k+2 \Rightarrow n^{2}=6\left(6 k^{2}+4 k\right)+4 ; \text { nije djeljivo sa } 6 \\
n= & 6 k+3 \Rightarrow n^{2}=6\left(6 k^{2}+6 k+1\right)+3 ; \text { nije djeljivo sa } 6 \\
n= & 6 k+4 \Rightarrow n^{2}=6\left(6 k^{2}+8 k+2\right)+4 \text {; nije djeljivo sa } 6 \\
n= & 6 k+5 \Rightarrow n^{2}=6\left(6 k^{2}+10 k+4\right)+1 ; \text { nije djeljivo sa } 6 .
\end{aligned}
$$

Tvrdnja vrijedi za svakog predstavnika ovih klasa, pa vrijedi za svaki prirodan broj. 


\subsection{Matematička indukcija}

Matematička indukcija ubraja se među Peanove aksiome skupa prirodnih brojeva, a koristi se za dokazivanje tvrdnji koje ovise o prirodnim brojevima u gotovo svim područjima matematike. Sastoji se od tri koraka.

Princip matematičke indukcije:

Neka je $P(n)$ neka tvrdnja, gdje je $n \in \mathbb{N}$.

(1) Baza indukcije: provjeravamo da tvrdnja vrijedi za prirodni broj 1

(2) Korak indukcije: pretpostavimo da tvrdnja vrijedi za proizvoljni $k \in \mathbb{N}$ i na osnovi pretpostavke dokazujemo da vrijedi za $k+1, \mathrm{tj}$. $P(k) \Rightarrow P(k+1)$,

(3) Zaključak: tvrdnja $P(n)$ vrijedi za svaki $n \in \mathbb{N}$.

Postoje različite varijante matematičke indukcije. Neke tvrdnje nisu istinite za prvih nekoliko prirodnih brojeva, ali se može dokazati da vrijede za sve prirodne brojeve $n$ veće od nekog $r \in \mathbb{N}$. U koraku indukcije dozvoljeno je pretpostaviti da $P(k)$ vrijedi za više od jedne vrijednosti $k$. Ponekad, da bismo uspjeli pokazati da je $P(k+1)$ istina, moramo koristiti i $P(k)$ i $P(k-1)$ i pretpostaviti da su obje tvrdnje istinite. Kompliciraniji slučajevi kombiniraju prethodno dvoje. Sljedeći je primjer poopćenje DeMorganovih zakona za skupove.

Teorem 6. Neka je $\mathcal{U}$ univerzalni skup, $A_{k} \in 2^{\mathcal{U}}$. Vrijedi

$$
\overline{\left(\bigcup_{k=1}^{n} A_{k}\right)}=\bigcap_{k=1}^{n} \overline{A_{k}}, \quad \text { za svaki } n \geq 2 \text {. }
$$

Dokaz. Neka je $P(n)$ tvrdnja $\overline{\left(\bigcup_{k=1}^{n} A_{k}\right)}=\bigcap_{k=1}^{n} \overline{A_{k}}$, za svaki $n \geq 2$. Vrijedi $\overline{\left(A_{1} \cup A_{2}\right)}=\overline{A_{1}} \cap \overline{A_{2}}$ (DeMorganovi zakoni) pa je $P(2)$ istina.

Pretpostavimo da tvrdnja vrijedi za broj $k \in \mathbb{N}$. Na osnovi pretpostavke dokažimo da vrijedi za $k+1$, tj. $P(k) \Rightarrow P(k+1), k \geq 2$. Iz $P(k+1)$ slijedi

$$
\begin{gathered}
=\overline{\left(A_{1} \cup A_{2} \cup \cdots \cup A_{k} \cup A_{k+1}\right)} \text { (asocijativnost) } \\
=\overline{\left(\left(A_{1} \cup A_{2} \cup \cdots \cup A_{k}\right) \cup A_{k+1}\right)}(\text { DeMorganovi zakoni) } \\
=\overline{\left(A_{1} \cup A_{2} \cup \cdots \cup A_{k}\right)} \cap \overline{A_{k+1}} \text { (po pretpostavci) } \\
=\left(\overline{A_{1}} \cap \overline{A_{2}} \cap \cdots \cap \overline{A_{k}}\right) \cap \overline{A_{k+1}} \text { (asocijativnost) } \\
=\overline{A_{1}} \cap \overline{A_{2}} \cap \cdots \cap \overline{A_{k}} \cap \overline{A_{k+1}} .
\end{gathered}
$$

Budući da iz istinitosti od $P(k)$ slijedi istinitost od $P(k+1)$ za svaki $k \in \mathbb{N}, k \geq 2$, zaključujemo da je $P(n)$ istinita tvrdnja za svaki $n \geq 2$. 
Teorem 7. Neka je $n \in \mathbb{N}$. Suma prvih $n$ prirodnih brojeva $S_{n}=1+$ $2+\cdots+n$ jednaka je $\frac{n(n+1)}{2}$.

Dokaz. Teorem ćemo dokazati na dva načina. Prvi način je korištenjem matematičke indukcije. Neka je $P(n)$ tvrdnja $S_{n}=1+2+\cdots+n=$ $\frac{n(n+1)}{2}$. Vrijedi

$$
S_{1}=1=\frac{1 \cdot 2}{2} \text { pa je } P(1) \text { istina. }
$$

Pretpostavimo da tvrdnja vrijedi za broj $k \in \mathbb{N}$. Na osnovi pretpostavke dokažimo da vrijedi za $k+1$, tj. $P(k) \Rightarrow P(k+1)$. Iz $P(k+1)$ slijedi

$$
\begin{gathered}
S_{n+1}=1+2+\cdots+n+(n+1) \\
=(1+2+\cdots+n)+(n+1)(\text { po pretpostavci) } \\
=\frac{n(n+1)}{2}+(n+1)=\frac{n(n+1)+2(n+1)}{2}=\frac{(n+1)(n+2)}{2} .
\end{gathered}
$$

Zaključujemo da je $P(n)$ istinita tvrdnja za svaki $n \geq 1$.

Drugi način da dokažemo teorem je možda ljepši i elegantniji te svakako pridonosi boljem razumijevanju rezultata.

Zapišimo $S_{n}$ na dva načina:

$$
\begin{aligned}
& S_{n}=1+2+\cdots+(n-1)+n \\
& S_{n}=n+(n-1)+\cdots+2+1
\end{aligned}
$$

te zbrojimo gornje dvije jednakosti. Dobit ćemo

$$
2 S_{n}=(n+1)+(n+1)+\cdots+(n+1)+(n+1)(n \text { puta }),
$$

odnosno

$$
2 S_{n}=n(n+1) \text { (dijeljenjem s } 2 \text { slijedi tvrdnja teorema). }
$$

\subsection{Dirichletov princip}

U rješavanju raznovrsnih problema, često je vrlo korisna i uspješna primjena jednog od najpoznatijih kombinatornih principa, Dirichletovog principa. Popularno ga se naziva i „princip golubinjaka”.

Princip kaže da ako $n+1$ predmeta (golubova) rasporedimo u $n$ kutija (krletki), onda postoji barem jedna kutija koja sadrži barem dva predmeta.

Formalnije, za bilo koje preslikavanje $f: A \rightarrow B$, ako je $\operatorname{card}(A)=$ $n+1, \operatorname{card}(B)=n$ postoje dva elementa iz $A$ koji imaju istu sliku u $B$.

Postoji i jači oblik Dirichletovog principa koji kaže da ako je $n$ predmeta smješteno u $m$ kutija, onda postoji barem jedna kutija koja sadrži barem $\left\lfloor\frac{n-1}{m}\right\rfloor+1$ predmeta. 
Primjer 8. Tablicu veličine $5 \times 5$ popunimo brojevima iz skupa $\{-1,0,1\}$. Izračunaju se sume u pojedinim retcima, stupcima $i$ na obje dijagonale. Dokažite da kako god tablica bila popunjena, među tim sumama postoje barem dvije jednake.

Rješenje. Ukupno ima 5 redaka, 5 stupaca i 2 dijagonale, što čini 12 mogućih mjesta za sume. Sume mogu biti od -5 do 5 i ima ih ukupno 11. $\mathrm{S}$ obzirom da 11 suma raspoređujemo na 12 mjesta, po Dirichletovom principu postoje barem dvije jednake sume.

\section{Važnost dokaza}

Dokaz je jako težak koncept za učenike, i učiteljima su jako dobro poznati problemi koje učenici i studenti imaju s konstruiranjem dokaza i s percepcijom potrebe za dokazom [11. Neke od poteškoća su notacijske (npr. višestruki kvantifikatori zbunjuju studente), zatim poteškoće s pojmom dokaza (npr. donošenje zaključka na temelju nekoliko primjera) i neučinkovite strategije dokazivanja. Učenici ne vide jasnu intelektualnu svrhu ili imaju duboko ukorijenjene pogrešne predodžbe što znači da je matematička tvrdnja valjana. Uzrok problema može biti u nekim udžbenicima koji za jednu izjavu nude intuitivno objašnjenje, za drugu izjavu daju primjer koji je potkrepljuje, a za treću rigorozni (formalni) dokaz, a da prijelaz između intuitivnog, empirijskog i formalnog nije dovoljno objašnjen.

Problemi s dokazom nisu samo zbog slabijeg kognitivnog razvoja (npr. nemogućnost logičkog zaključivanja) jer, po nekim istraživanjima, čak su i vrlo mala djeca sposobna logički zaključivati u situacijama koje su stvarne i značajne za njih. Razlog zbog kojeg učenici nisu toliko uključeni u dokazivanje nije taj što ne mogu, već ne vide razloge ili potrebu za logičkim dokazima, posebno kada su ti dokazi vizualno očiti ili se empirijski mogu lako provjeriti [1]. Na učiteljima je da tu potrebu potiču, te iskoriste nesigurnost i kognitivni sukob kao pokretačku snagu za stvaranje potrebe za dokazima. Učenici, kao i profesionalni matematičari imaju istu potrebu za svrhovitim aktivnostima koje uključju znanje, shvaćanje i doživljaj korisnosti aktivnosti u koje su uključeni [9].

Dokaz je živo tkivo matematike i zaslužuje istaknuto mjesto u kurikulumu matematike, imajući u vidu da su u učionici ključne uloge dokaza ipak provjeravanje i promicanje matematičkog razumijevanja. U učionici glavno pitanje na koje dokaz mora odgovoriti jest zašto [4]. Treba se promijeniti percepcija učenika što matematika jest (matematika nije samo ono što matematika „radi”). Za ulazak u svijet matematike potrebno je koristiti apstraktne ideje i matematički dokaz [7]. 
Dokazi uče studente konceptima i tehnikama potrebnima u rješavanju problema, razvijanju vještina logičkog zaključivanja, uče ih testiranju pretpostavki tako da mogu raditi na način koji nije samo unošenje brojeva u neke modele, nego im daju samopouzdanje da mogu rješavati nove probleme.

\section{Literatura}

[1] I. Babić, Dokazi u nastavi matematike, diplomski rad, 2017.

[2] N. Baranović, Struktura matematike, prezentacija u Centru izvrsnosti, 2017.

[3] G. Hanna, Challenges to the importance of proof , 1995.

[4] G. Hanna, Proof, Explanation and Exploration: An Overview, 2000.

[5] K. Hemmi, C. Lofwall, Why do we need proof, 2009.

[6] Z. Kurnik, Dokaz, Matematika i škola 9, 2001.

[7] M. Petrač, Matematički dokaz, Osječki matematički list 14 (2014), $157-166$.

[8] A. Stefanowicz, Proofs and Mathematical Reasoning, University of Birmingham, 2014.

[9] M. de Villiers, The role and function of proof in mathematics, 1990.

[10] D. Žubrinić, Diskretna matematika, Element, 2001.

[11] https://www.maa.org/programs/faculty-and-departments/ curriculum-department-guidelines-recommendations/ teaching-and-learning/research-sampler-8-studentsdifficulties-with-proof (Datum zadnjeg pristupa: 2.9.2020.)

Ivana Grgić

Sveučilište u Splitu, Fakultet elektrotehnike, strojarstva i brodogradnje, Ruđera Boškovića 32, 21000 Split, Hrvatska

E-mail adresa: ipletiko@fesb.hr 